\title{
Relation between fractures and mortality: results from the Canadian Multicentre Osteoporosis Study
}

\author{
George loannidis PhD, Alexandra Papaioannou MD, Wilma M. Hopman MSc, \\ Noori Akhtar-Danesh PhD, Tassos Anastassiades MD, Laura Pickard MA, \\ Courtney C. Kennedy MSc, Jerilynn C. Prior MD, Wojciech P. Olszynski MD PhD, \\ Kenneth S. Davison PhD, David Goltzman MD, Lehana Thabane PhD, Amiran Gafni PhD, \\ Emmanuel A. Papadimitropoulos PhD, Jacques P. Brown MD, Robert G. Josse MD, \\ David A. Hanley MD, Jonathan D. Adachi MD
}

Previously published at www.cmaj.ca on Aug. 3, 2009.

$\infty \infty$

See related research paper by Ashe and Khan

\section{ABSTRACT}

Background: Fractures have largely been assessed by their impact on quality of life or health care costs. We conducted this study to evaluate the relation between fractures and mortality.

Methods: A total of 7753 randomly selected people (2187 men and 5566 women) aged 50 years and older from across Canada participated in a 5-year observational cohort study. Incident fractures were identified on the basis of validated self-report and were classified by type (vertebral, pelvic, forearm or wrist, rib, hip and "other"). We subdivided fracture groups by the year in which the fracture occurred during follow-up; those occurring in the fourth and fifth years were grouped together. We examined the relation between the time of the incident fracture and death.

Results: Compared with participants who had no fracture during follow-up, those who had a vertebral fracture in the second year were at increased risk of death (adjusted hazard ratio [HR] 2.7, 95\% confidence interval [CI] 1.1-6.6); also at risk were those who had a hip fracture during the first year (adjusted HR 3.2, 95\% Cl 1.4-7.4). Among women, the risk of death was increased for those with a vertebral fracture during the first year (adjusted HR 3.7, 95\% Cl 1.1-12.8) or the second year of follow-up (adjusted HR 3.2, 95\% Cl 1.2-8.1). The risk of death was also increased among women with hip fracture during the first year of follow-up (adjusted HR 3.0, 95\% Cl 1.0-8.7).

Interpretation: Vertebral and hip fractures are associated with an increased risk of death. Interventions that reduce the incidence of these fractures need to be implemented to improve survival.

Une version française de ce résumé est disponible à l'adresse www.cmaj.ca/cgi/content/full/cmaj.081720/DC1
$\mathrm{O}$ steoporosis-related fractures are a major health concern, affecting a growing number of individuals worldwide. The burden of fracture has largely been assessed by the impact on health-related quality of life and health care costs. ${ }^{1,2}$ Fractures can also be associated with death. However, trials that have examined the relation between fractures and mortality have had limitations that may influence their results and the generalizability of the studies, including small samples, ${ }^{3,4}$ the examination of only 1 type of fracture, ${ }^{4-10}$ the inclusion of only women, ${ }^{8,11}$ the enrolment of participants from specific areas (i.e., hospitals or certain geographic regions), ${ }^{3,4,7,8,10,12}$ the nonrandom selection of participants ${ }^{3-11}$ and the lack of statistical adjustment for confounding factors that may influence mortality., $3,5-7,12$

We evaluated the relation between incident fractures and mortality over a 5-year period in a cohort of men and women 50 years of age and older. In addition, we examined whether other characteristics of participants were risk factors for death.

\section{Methods}

\section{Study design and population}

Details about the purpose and methodology of the Canadian Multicentre Osteoporosis Study have been reported previously. ${ }^{13}$ The Canadian Multicentre Osteoporosis Study is a large prospective trial that provides substantial data on fractures

\footnotetext{
From the Departments of Medicine (Ioannidis, Papaioannou, Pickard, Kennedy, Adachi), Nursing (Akhtar-Danesh) and Clinical Epidemiology and Biostatistics (Thabane, Gafni), McMaster University, Hamilton, Ont.; the Departments of Community Health and Epidemiology (Hopman) and Medicine (Anastassiades), Queen's University, Kingston, Ont.; the Department of Medicine (Prior), University of British Columbia, Vancouver, BC; the Department of Medicine (Olszynski), University of Saskatchewan, Saskatoon, Sask.; the Department of Medicine (Brown, Davison), Laval University, Sainte-Foy, Que.; the Department of Medicine (Goltzman), McGill University, Montréal, Que.; Outcomes Research (Papadimitropoulos), Eli Lilly and Company, Toronto, Ont.; the Department of Medicine (Josse), University of Toronto, Toronto, Ont., and the Department of Medicine (Hanley), University of Calgary, Calgary, Alta.
}

Cite as CMAJ 2009. DOI:10.1503/cmaj.081720 
and mortality. In brief, this ongoing population-based cohort study involves an age-, sex- and region-specific sample of the Canadian population. The sample comprises 9423 people (2885 men, 6538 women) 25 years of age and older living in the community within $50 \mathrm{~km}$ of 9 study centres (St. John's, Newfoundland and Labrador; Halifax, Nova Scotia; Québec City, Quebec; Kingston, Toronto and Hamilton, Ontario; Saskatoon, Saskatchewan; Calgary, Alberta; and Vancouver, British Columbia). The catchment area for each centre captures both urban and rural areas, although Toronto and Vancouver are primarily urban. This sample framework represents about $40 \%$ of the Canadian population.
The sampling frame consisted of all residential telephone subscribers. Provincial telephone companies created random samples in lots of 10000 of all their subscribers within specified postal code areas. Informed consent was obtained from each individual. The Canadian Multicentre Osteoporosis Study received approval by the institutional review boards at each participating centre.

For our study, we included participants of the Canadian Multicentre Osteoporosis Study who were 50 years of age and older.

\section{Data collection at study entry}

Information collected at study enrolment included data from

Table 1: Baseline characteristics of 7753 participants enrolled in an observational study of the relation between fractures and mortality

\begin{tabular}{|c|c|c|c|}
\hline Characteristic & Total & Men & Women \\
\hline \multicolumn{4}{|l|}{ Anthropometry/demographic, mean (SD; $N$ ) } \\
\hline Weight, kg & $72.1(14.8 ; 7542)$ & $81.2(13.8 ; 2133)$ & $68.5(13.6 ; 5409)$ \\
\hline Height, $\mathrm{cm}$ & $163.0 \quad(9.0 ; 7526)$ & $172.8(7.1 ; 2132)$ & $159.1 \quad(6.4 ; 5394)$ \\
\hline Age, yr & $66.7 \quad(9.3 ; 7753)$ & $66.3(9.5 ; 2187)$ & $66.8 \quad(9.3 ; 5566)$ \\
\hline \multicolumn{4}{|l|}{ Use of medications, \% $(n / N)$} \\
\hline Hormone replacement therapy & NA & NA & $24.5(1362 / 5566)$ \\
\hline Corticosteroid & $0.6 \quad(49 / 7753)$ & $0.3 \quad(7 / 2187)$ & $0.8 \quad(42 / 5566)$ \\
\hline Bisphosphonate & $2.0(157 / 7753)$ & $0.2 \quad(4 / 2187)$ & $2.7(153 / 5566)$ \\
\hline Education, some university or higher, $\%(n / N)$ & $24.5(1899 / 7752)$ & $33.5(733 / 2186)$ & $20.9(1166 / 5566)$ \\
\hline \multicolumn{4}{|l|}{ Prior fracture status, $\%(n / N)$} \\
\hline Clinically recognized minimal trauma fractures & $16.0(1237 / 7752)$ & $8.5(186 / 2186)$ & $18.9(1051 / 5566)$ \\
\hline \multicolumn{4}{|l|}{ Diseases, * \% $(n / N)$} \\
\hline 0 & $26.3(2041 / 7753)$ & $32.4(708 / 2187)$ & $23.9(1333 / 5566)$ \\
\hline 1 & $32.2(2495 / 7753)$ & $33.3(729 / 2187)$ & $31.7(1766 / 5566)$ \\
\hline 2 & $22.5(1744 / 7753)$ & $20.3(444 / 2187)$ & $23.4(1300 / 5566)$ \\
\hline 3 & 11.7 (907/7753) & $9.3(204 / 2187)$ & $12.6(703 / 5566)$ \\
\hline$\geq 4$ & $7.3(566 / 7753)$ & $4.7(102 / 2187)$ & $8.3(464 / 5566)$ \\
\hline \multicolumn{4}{|l|}{ Prior surgeries, $\dagger \%(n / N)$} \\
\hline 0 & $74.2(5756 / 7753)$ & $82.6(1807 / 2187)$ & $70.9(3949 / 5566)$ \\
\hline 1 & $22.2(1718 / 7753)$ & $15.2(332 / 2187)$ & $24.9(1386 / 5566)$ \\
\hline$\geq 2$ & $3.6(279 / 7753)$ & $2.2 \quad(48 / 2187)$ & $4.2(231 / 5566)$ \\
\hline \multicolumn{4}{|l|}{ Health-related habits } \\
\hline Caffeine intake, mg/d, mean (SD; $N$ ) & $280.8(259.0 ; 7718)$ & $328.4(301.9 ; 2180)$ & $262.1(237.5 ; 5538)$ \\
\hline Vitamin D intake, IU/d, mean (SD; $N$ ) & $217.2(377.4 ; 7753)$ & $90.0(287.5 ; 2187)$ & $187.5(672.3 ; 5566)$ \\
\hline Calcium intake, mg/d, mean (SD; $N$ ) & $160.0(591.4 ; 7753)$ & $95.3(248.0 ; 2187)$ & $265.1(407.6 ; 5566)$ \\
\hline Alcohol consumption, drinks/yr, mean (SD; $N$ ) & $150.4(304.9 ; 7740)$ & $273.3(441.0 ; 2182)$ & $102.2(211.8 ; 5558)$ \\
\hline Regular physical activity, $\%(n / N)$ & $55.4(4297 / 7753)$ & $55.6(1215 / 2187)$ & $55.4(3082 / 5566)$ \\
\hline Current smoker, $\%(n / N)$ & $14.8(1147 / 7753)$ & $18.0(393 / 2187)$ & $13.5(754 / 5566)$ \\
\hline \multicolumn{4}{|l|}{ Quality-of-life score, $\neq$ mean $(S D ; N)$} \\
\hline Standardized physical subscale & $46.2(10.4 ; 7706)$ & $47.6(9.6 ; 2178)$ & $45.7(10.6 ; 5528)$ \\
\hline Standardized mental health subscale & $53.8(8.6 ; 7706)$ & $54.7(7.8 ; 2178)$ & $53.4 \quad(8.9 ; 5528)$ \\
\hline
\end{tabular}

Note: $\mathrm{NA}=$ not applicable, SD = standard deviation.

*Diseases were self-reported and included rheumatoid arthritis, osteoarthritis, thyroid disease (hyperthyroidism, hypothyroidism), liver disease, scoliosis, breast cancer, uterine cancer, inflammatory bowel disease, kidney disease, hypertension, myocardial infarction, stroke, neuromuscular disease (Parkinson disease, multiple sclerosis, other), type 1 and type 2 diabetes mellitus, phlebitis or thrombophlebitis, prostate cancer and Paget disease. tPrior surgeries were self-reported and included parathyroid, thyroid, gastric, intestinal and gall bladder surgery. ¥As measured by the Medical Outcomes Study 36-item Short Form (SF-36). ${ }^{15}$ 
questionnaires and a number of physical measurements. To determine potential risk factors for death, we investigated individual characteristics of participants if, on the basis of clinical judgment, they were considered clinically associated with death or if they were stated as risk factors in the 2002 clinical practice guidelines for the diagnosis and management of osteoporosis in Canada. ${ }^{14}$ We classified characteristics into 6 categories: anthropometric and demographic characteristics; medications; status of prevalent fractures; number of diseases and prior surgeries; health-related habits; and quality-of-life measurements. The anthropometric and demographic characteristics were age, sex, study centre, height, weight and educational status (no university v. some university). Medications identified for analysis were hormone replacement therapy, corticosteroids and bisphosphonate. Status of prevalent fractures included clinically recognized minimal trauma fractures (caused by a fall from standing height or lower while sitting, standing or walking) reported at enrolment and vertebral fractures identified radiographically at enrolment. Health-related habits included caffeine intake, calcium intake from supplements and drugs, vitamin D intake from supplements and drugs, alcohol intake, regular physical activity and smoking status. Quality of life was measured with use of the Medical Outcomes Trust SF-36 Health Survey; ${ }^{15}$ this tool comprises 2 components, the standardized physical subscale and the standardized mental health subscale. A 2-3 point difference in summary score is considered clinically meaningful. ${ }^{16}$

To identify morphometric vertebral fractures at study entry, spinal radiographs were performed under standardized conditions. The radiographs were quantitatively examined for vertebral fractures using a digital graphics tablet. Vertebral bodies were examined by measuring the anterior, middle and posterior heights of lateral thoracic and lumbar bodies on the radiographs. The vertebral heights were used to calculate 4 height ratios: a vertebra was considered fractured if the height ratio was greater than 3 standard deviations below the mean normal ratio. ${ }^{17}$

\section{Annual assessment of fractures}

Clinically recognized incident fractures were identified on the basis of self-reports documented in the questionnaire mailed annually. Participants who reported fractures were asked for consent to contact the treating physician or hospital for verification and for acquisition of further details.

For the purposes of our study, we separated participants into 7 groups according to the type of incident fracture: vertebral, pelvic, forearm or wrist, rib, hip, "other" fracture and no fracture. "Other" included any fracture except for those specified above and those involving the toes, fingers or face. For the analyses, we subdivided the groups further according to the year in which the fracture occurred during follow-up. Participants who had fractures in the last 2 years of follow-up were grouped together. We considered participants who had no incident fractures as the reference group.

\section{Mortality}

Deaths that occurred during the follow-up period were ascertained through mail or phone contact with a member of the participant's family. In some centres, obituaries were also reviewed to identify deceased participants.

\section{Statistical analysis}

To determine the relation between time of incident fracture and time to death, we used a 2-step process. First, we conducted individual Cox proportional hazard analyses to determine important covariates to include in the final model; all variables with a $p$ value of less than 0.2 were included. Second, the time of the incident fracture was forced in the final model.

To determine all potential risk factors for death, we conducted a multivariable Cox proportional hazard analysis that included all characteristics of participants classified in the 6 categories. The final model was chosen using a forward selection procedure.

Analyses were conducted for all participants combined and for men and women separately. For the combined analysis, several interactions were examined, including sex by age and sex by fracture status. None of the interactions was found to be significant. We used the exact method to handle tied event times in the analyses. For each model, we report adjusted hazard ratios (HRs) and 95\% confidence intervals (CIs). Because time of study entry is incidental to modelling HRs, we based the time scale used in these analyses on age rather than on elapsed time from study entry. Specifically, the participant's age at study enrolment was considered the time of entry into the risk set; the age when last observed (either owing to censoring or an event) was considered the time of departure from the risk set.

\section{Results}

A total 7753 participants, 2187 men and 5566 women aged 50 years and older participated in our study (Table 1). The number of participants who had clinically recognized incident fractures during the follow-up period is shown in Table 2. All types of fracture were more common among women than among men except for rib fractures.

The unadjusted HRs and 95\% CIs for each fracture type and time to death are presented in Table 3 . The absolute rates of death were the same among men and women with hip fracture (23.5\% in each group) and slightly higher among men with vertebral fractures (18.2\% among men v. $15.7 \%$ among women) (Table 4). Factors that were related to death and that were common to both men and women included educational

Table 2: Incidence of fractures during the 5-year follow-up period, by type of fracture

\begin{tabular}{lrrr}
\hline & \multicolumn{3}{c}{ No. (\%) of participants } \\
\cline { 2 - 4 } Type of fracture & $\begin{array}{c}\text { Total } \\
n=7693\end{array}$ & $\begin{array}{c}\text { Men } \\
n=2163\end{array}$ & $\begin{array}{c}\text { Women } \\
n=5530\end{array}$ \\
\hline Vertebral* & $100(1.3)$ & $11(0.5)$ & $89(1.6)$ \\
\hline Pelvic & $23(0.3)$ & $3(0.1)$ & $20(0.4)$ \\
\hline Forearm or wrist & $199(2.6)$ & $26(1.2)$ & $173(3.1)$ \\
\hline Rib & $147(1.9)$ & $45(2.1)$ & $102(1.8)$ \\
\hline Hip & $85(1.1)$ & $17(0.8)$ & $68(1.2)$ \\
\hline Othert & $305(4.0)$ & $63(2.9)$ & $242(4.4)$ \\
\hline
\end{tabular}

*Vertebral fractures included those that were clinically recognized and not those identified on the basis of morphometric measurements.

tIncludes any fracture except those specified above and those involving the toes, fingers or face. 
status, number of diseases, regular physical activity, smoking status and the quality-of-life SF-36 standardized physical subscale score (Appendix 1, available at www.cmaj.ca/cgi /content/full/cmaj.081720/DC2).

For the analyses of men and women combined, adjusted results showed an increased risk of death among participants

\begin{tabular}{|c|c|c|c|}
\hline \multirow{2}{*}{$\begin{array}{l}\text { Time to fracture } \\
\text { during follow-up }\end{array}$} & \multicolumn{3}{|c|}{ Hazard ratio $(95 \% \mathrm{Cl})$} \\
\hline & Total & Men & Women \\
\hline Vertebral* & 1.00 & 1.00 & 1.00 \\
\hline \multicolumn{4}{|l|}{ Nonet } \\
\hline In first year & $2.53(0.94-6.85)$ & $2.29(0.31-17.01)$ & $2.85(0.90-9.07)$ \\
\hline In second year & $2.27(1.09-4.73) \S$ & NA & $2.65(1.24-5.63) \S$ \\
\hline In third year & $0.62(0.15-2.52)$ & NA & $0.68(0.17-2.80)$ \\
\hline In fourth or fifth year & NA & NA & NA \\
\hline \multicolumn{4}{|l|}{ Pelvic } \\
\hline Nonet & 1.00 & 1.00 & 1.00 \\
\hline In first year & $1.71(0.42-6.94)$ & NA & $2.29(0.55-9.44)$ \\
\hline In second year & $1.24(0.17-9.28)$ & NA & $1.55(0.20-12.05)$ \\
\hline In third year & NA & NA & NA \\
\hline In fourth or fifth year & NA & NA & NA \\
\hline \multicolumn{4}{|l|}{ Forearm or wrist } \\
\hline Nonet & 1.00 & 1.00 & 1.00 \\
\hline In first year & $1.01(0.38-2.71)$ & NA & $1.36(0.50-3.68)$ \\
\hline In second year & $1.94(0.87-4.35)$ & $3.00(0.41-21.76)$ & $2.05(0.85-4.99)$ \\
\hline In third year & $0.81(0.26-2.52)$ & $1.86(0.23-15.23)$ & $0.79(0.20-3.18)$ \\
\hline In fourth or fifth year & $0.58(0.21-1.59)$ & $1.09(0.14-8.20)$ & $0.56(0.17-1.82)$ \\
\hline \multicolumn{4}{|l|}{ Rib } \\
\hline Nonet & 1.00 & 1.00 & 1.00 \\
\hline In first year & $1.27(0.47-3.43)$ & $1.63(0.23-11.73)$ & $1.32(0.42-4.18)$ \\
\hline In second year & $1.94(0.84-4.46)$ & $0.97(0.12-7.96)$ & $2.21(0.88-5.59)$ \\
\hline In third year & $0.58(0.07-4.61)$ & NA & $1.11(0.14-9.11)$ \\
\hline In fourth or fifth year & NA & NA & NA \\
\hline \multicolumn{4}{|l|}{ Hip } \\
\hline Nonet & 1.00 & 1.00 & 1.00 \\
\hline In first year & $4.19(1.83-9.61) \S$ & $4.13(0.98-17.39)$ & $4.31(1.53-12.13) \S$ \\
\hline In second year & $0.97(0.36-2.64)$ & NA & $1.14(0.41-3.15)$ \\
\hline In third year & $1.62(0.52-5.07)$ & NA & $1.89(0.60-5.96)$ \\
\hline In fourth or fifth year & $0.56(0.23-1.39)$ & $0.51(0.07-3.82)$ & $0.58(0.21-1.61)$ \\
\hline \multicolumn{4}{|l|}{ Other‡ } \\
\hline Nonet & 1.00 & 1.00 & 1.00 \\
\hline In first year & $0.54(0.20-1.46)$ & $0.40(0.06-2.82)$ & $0.60(0.19-1.90)$ \\
\hline In second year & $1.26(0.67-2.37)$ & $1.09(0.34-3.45)$ & $1.35(0.64-2.88)$ \\
\hline In third year & $1.27(0.53-3.08)$ & $3.56(1.31-9.66) \S$ & $0.38(0.05-2.74)$ \\
\hline In fourth or fifth year & $0.25(0.06-1.02)$ & NA & $0.36(0.09-1.46)$ \\
\hline
\end{tabular}

Note: $\mathrm{Cl}=$ confidence interval, $\mathrm{NA}=$ not applicable owing to the lack of fractures during this period *Vertebral fractures included those that were clinically recognized and not those identified on the basis of morphometric measurements.

tReference group.

FIncludes any fracture except those specified above and those involving the toes, fingers or face. $\S$ Statistically significant result $(p<0.05)$ with vertebral fracture during the second year of follow-up (adjusted HR 2.7, 95\% CI 1.1-6.6) and among those with hip fracture during the first year of follow-up (adjusted HR 3.2, 95\% CI 1.4-7.4), as compared with participants with no incident fractures. Participants who had incident "other" fractures in the fourth and fifth years were less likely to die than those who had no fracture. Among women, those with vertebral fractures were at increased risk of death if the fracture occurred in the first year of follow-up (adjusted HR 3.7, 95\% CI 1.1-12.8) or the second year of follow-up (adjusted HR 3.2, 95\% CI 1.2-8.1). Also at increased risk of death were women with hip fracture that occurred in the first year of follow-up (adjusted HR 3.0, 95\% CI 1.0 8.7 ), as compared with women without these fractures. The relation between fractures and mortality among men was inconclusive (Figure 1, Figure 2, Appendix 2, available at www.cmaj.ca/cgi/content/full /cmaj.081720/DC2).

Predictors of death in the combined group of participants were vertebral fracture (first year after fracture adjusted HR 3.00 , 95\% CI 1.10-8.17; second year after fracture adjusted HR 2.78, 95\% CI 1.23 6.31) and hip fracture (first year adjusted HR 3.52, 95\% CI 1.54-8.03). Other predictors of death in the combined group were age (adjusted HR 0.90, 95\% CI 0.85-0.95); some university education (adjusted HR 0.65 , 95\% CI 0.51-0.82); being female (adjusted HR 0.46, 95\% CI 0.39-0.55); having 4 or more diseases (adjusted HR 1.73, 95\% CI 1.25-2.38); caffeine intake more than $100 \mathrm{mg} /$ day (adjusted HR 0.96, 95\% CI 0.92-0.99); no regular physical activity (adjusted HR 1.33, 95\% CI 1.11-1.58); current smoker (adjusted HR 2.30, 95\% CI 1.85-2.86); and a score of 10 points on the SF-36 standardized physical subscale (adjusted HR 0.73, 95\% CI 0.67-0.80). "Other" fractures were a predictor of death in the fourth or fifth year after fracture in the combined group (adjusted HR 0.13, 95\% CI 0.02-0.90) (Appendix 3, available at www.cmaj.ca/cgi/content/full/cmaj

\section{.081720/DC2)}

Predictors common to women and men included age (adjusted HR for men 0.91, 95\% CI 0.82-0.99; adjusted HR for women $0.89,95 \%$ CI 0.83-0.96); regular physical activity (adjusted HR for men 1.49, 95\% CI 1.13-1.96; adjusted HR for women 1.32, 95\% CI 1.05-1.66); current smoker (adjusted HR for men 1.76, 95\% 
CI 1.25-2.47; adjusted HR for women $2.71,95 \%$ CI 2.07-3.55); and a score of 10 on the SF-36 standardized physical subscale (adjusted HR for men 0.71, 95\% CI 0.62-0.81; adjusted HR for women $0.71,95 \%$ CI 0.64-0.79) (Appendix 3, available at www.cmaj.ca/cgi/content/full/cmaj.081720/DC2).

\section{Interpretation}

Our results demonstrated that, among participants aged 50 years and older, those with hip or vertebral fractures were more likely to die during the 5 years of follow-up than were those without these fractures. In addition, our results showed that hip fractures may have long-lasting effects that result in eventual death by signaling or actually inducing a progressive decline in health. Our results also showed that vertebral fracture was an independent predictor of death. Fractures of the forearm or wrist and ribs had no impact on mortality. These findings confirm those from other studies. $3,6,8,11,18,19$

In contrast to studies that have shown increased mortality among men with fractures than among women with fractures, ${ }^{10,20}$ our adjusted findings showed no sex-related differences. Perceived differences may be due to other individual characteristics that are not distributed equally among men and women and not controlled for in the analyses. ${ }^{20}$ For instance, compared with women, men may have poor underlying health, more disease conditions and less social support. ${ }^{20}$ Nonetheless, our study may have had insufficient power to detect sexrelated differences.

The strengths of our study are numerous. The participants were selected randomly from population lists that represent an age-, sex- and region-specific sample of the Canadian population. A large number of women and men across Canada were evaluated, which improves the generalizability of the results. Radiographs were systematically performed at baseline to confirm all prevalent vertebral fractures. We examined several types of osteoporotic fractures, including the infrequently studied pelvic and rib fractures. Furthermore, because mortality and fractures are largely a problem of older people with comorbidities, we adjusted our analysis for factors that may influence mortality, such as the number of diseases, use of medications, health-related habits and quality of life.

The distinct characteristics of our study, which previous studies examining the relation between fracture and mortality have lacked, strengthen our ability to suggest a causal relation between fractures and mortality. First, the strength of the associations was strong, with the majority of significant HRs being about 3 . Thus, it is unlikely that the associations were by chance. Temporally, the relation is correct, fractures precede death. In addition, the associations differed depending on the type of fracture. We found that only vertebral and hip fractures were associated with death. Moreover, the relation between fracture and death is biologically plausible, and theories exist as to why fractures cause death. For example, 2 theories have been proposed to clarify the association between hip fractures and death. The first suggests that frail elderly people who have a number of comorbidities will die quickly following a fracture. A hip fracture is simply one event in a series of late-life illnesses that increases such a person's likelihood of dying. The second theory involves healthy elderly people without notable comorbidities. Such people are better able to endure the initial consequences of a hip fracture because of their superior health and coping abilities. Their progressive decline in health may be caused by a lack of mobility and a loss of strength and muscle mass, which results in increased disability and other negative health consequences. ${ }^{11}$ Vertebral fractures probably influence death directly because of their association with chronic back pain, immobility and change in posture, which may increase the risk of infection. ${ }^{21}$ Finally, fractures have been found to have many other negative consequences such as increased pain, immobility and reduced health-related quality of life.

Our finding that participants with fractures in the "other" category during the fourth or fifth year of follow-up were less likely to die than those without such fractures is difficult to interpret. This is because of the large number of types of fracture in this category and the potential differences in rates of death associated with individual fracture types.

We found that several other factors were related to mortality. As expected, smoking status, regular physical activity and number of diseases had a major impact on mortality. Participants with at least some university education were less likely than those with no university education to die during the follow-up period. It has been postulated that people with lower education levels are at increased risk of death because of their lower socio-economic status. ${ }^{22,23}$

\section{Limitations}

Our study has limitations. Although we included several potential confounding variables in the analysis, not all risk factors may have been adequately captured in the Canadian Multicentre Osteoporosis Study data set. In addition, only new, clinically recognized vertebral fractures were examined (not vertebral fractures identified on the basis of morphometric measurements). Thus, a large proportion of incident vertebral fractures may not have been recognized. However, it has been shown that 
radiographically identified vertebral fractures have less impact on mortality than clinically recognized fractures and thus may not be important. ${ }^{24}$ Moreover, because of the small number of fractures at certain anatomic sites, particularly in men, and the fewer men than women in the stratified recruitment sample, results were inconclusive (given the wide CIs). Furthermore, because of the limited number of multiple fractures by fracture type, we could not address the influence of multiple fractures on

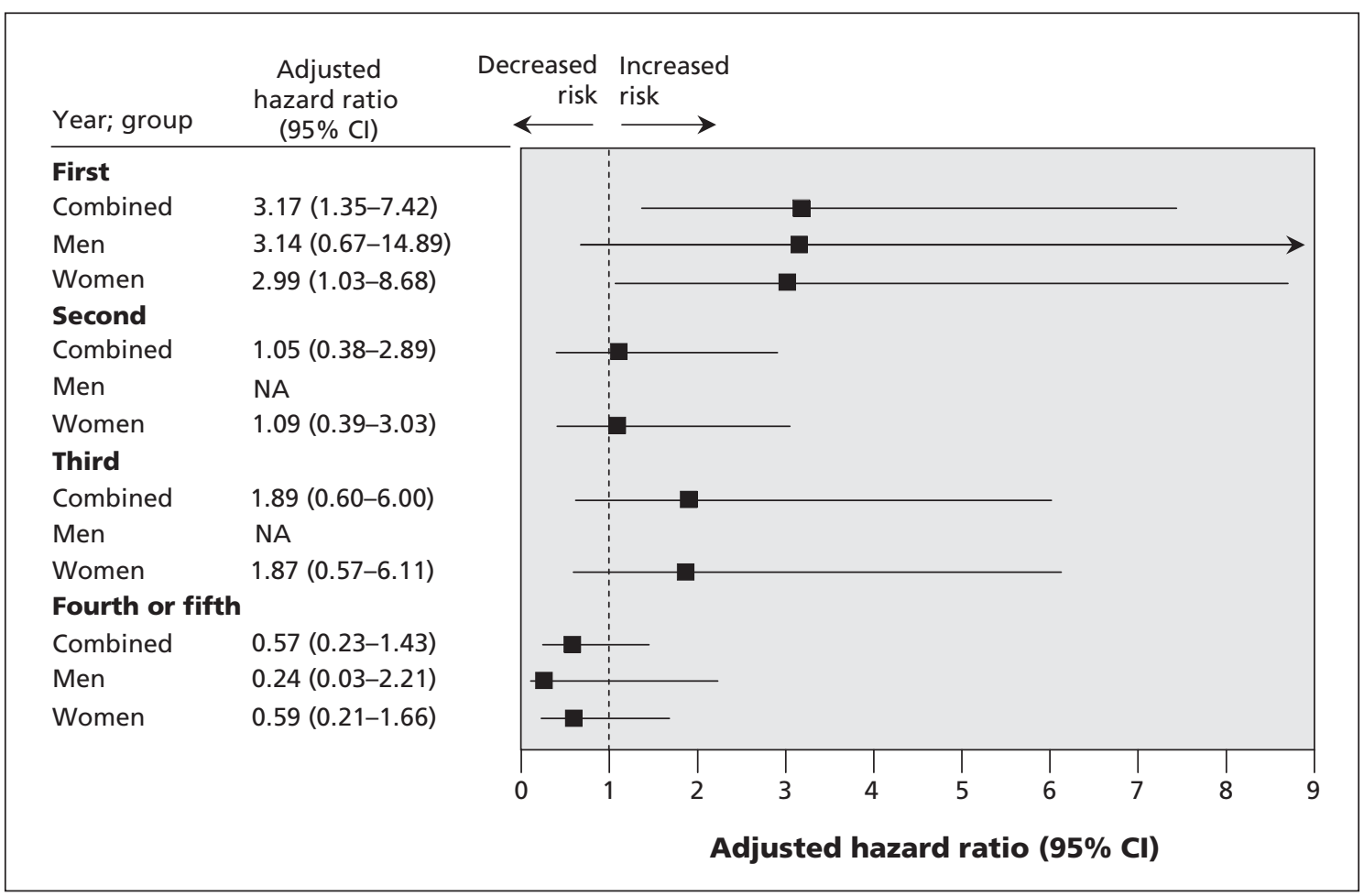

Figure 1: Adjusted* hazard ratios of death among participants with incident hip fracture and death. Adjustments were made for the variables listed in Table 1. Note: $\mathrm{Cl}=$ confidence interval.

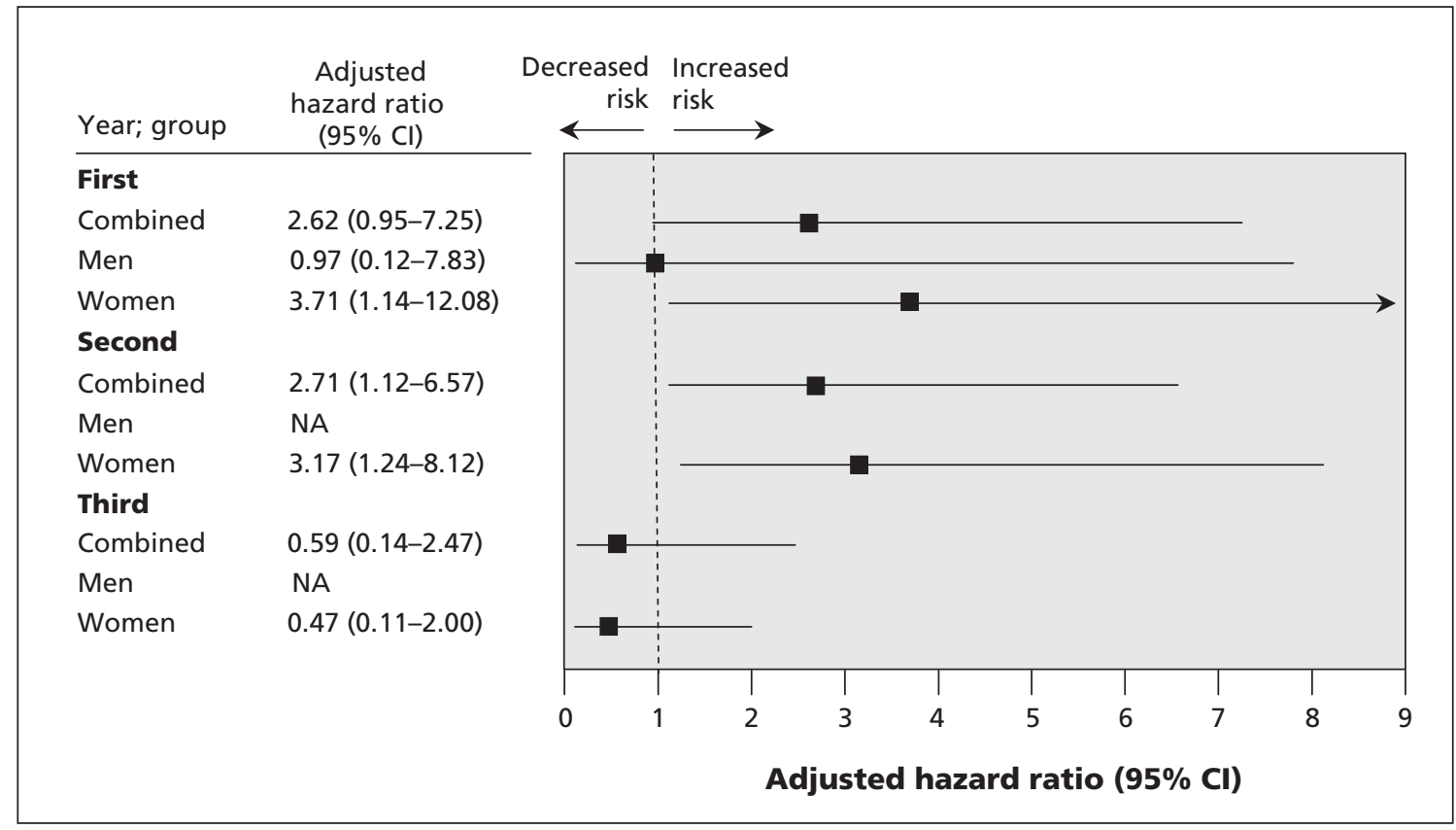

Figure 2: Adjusted hazard ratios of death among participants with incident vertebral fracture and death. Adjustments were made for the variables listed in Table 1. Note: $\mathrm{Cl}=$ confidence interval. 
mortality. Finally, the study involved ambulatory participants living in the community. We did not evaluate the relation between hip fractures and short-term mortality among people in long-term care facilities, who are likely more frail.

\section{Conclusion}

Our results show a strong association between vertebral and hip fractures and death. Given this association, interventions need to be implemented to reduce the likelihood that patients will experience fractures that increase their risk of death. These might include the use of interventions such as osteoporosis medications, strategies to prevent falls or the use of hip protectors.

\section{This article has been peer reviewed.}

Competing interests: Alexandra Papaioannou is or has been a consultant or on a speaker's bureau for Amgen, Aventis Pharma, Eli Lilly, Merck Frosst Canada, Novartis, Procter \& Gamble Pharmaceuticals, Servier and Wyeth-Ayerst; she has conducted clinical trials for Eli Lilly, Merck Frosst Canada, Novartis, Procter \& Gamble Pharmaceuticals and Sanofi-Aventis; and she has received unrestricted grants from Amgen, Eli Lilly, Merck Frosst Canada, Procter \& Gamble Pharmaceuticals and Sanofi-Aventis. David Goltzman has been a member of the advisory board on osteoporosis for Eli Lilly, Novartis, Proctor \& Gamble Pharmaceuticals, Sanofi-Aventis and Merck; he has been a member of the Data Safety Monitoring Board for Denosumab of Amgen. Emmanuel Papadimitropoulos is an employee of Eli Lilly. Robert Josse is a member of the advisory board for Procter \& Gamble Pharmaceuticals, Sanofi-Aventis, Novartis, Servier, Amgen and Eli Lilly; none of these activities have any relation to the content of the article. Jonathan Adachi has been a consultant or on a speaker's bureau for Amgen, Astra Zeneca, Eli Lilly, GlaxoSmithKline, Merck Frosst Canada, Novartis, Nycomed, Pfizer, Procter \& Gamble Pharmaceuticals, Roche, SanofiAventis, Servier, Wyeth-Ayerst and Bristol-Myers Squibb; he has conducted clinical trials for Amgen, Eli Lilly, GlaxoSmithKline, Merck Frosst Canada, Novartis, Pfizer, Procter \& Gamble Pharmaceuticals, Sanofi-Aventis, Roche, Wyeth and Bristol-Myers Squibb. Wojciech Olszynski has been a consultant or on a speaker's bureau for Amgen, Eli Lilly, Merck Frosst Canada, Novartis, Pfizer, Procter \& Gamble Pharmaceuticals and Sanofi-Aventis, and he has conducted clinical trials for Procter \& Gamble Pharmaceuticals. Jacques Brown is or has been a consultant or on a speaker's bureau for Procter \& Gamble Pharmaceuticals, Sanofi-Aventis, Novartis and Merck Frosst Canada. He has conducted clinical trials for Amgen, Procter \& Gamble Pharmaceuticals, Sanofi-Aventis, Novartis and Merck Frosst Canada, and he has been a member of advisory board on osteoporosis for Amgen, Procter \& Gamble Pharmaceuticals and Sanofi-Aventis, and Novartis. David Hanley has been a consultant or on a speaker's bureau for Amgen, Eli Lilly, Merck Frosst Canada, Novartis, Pfizer, Procter \& Gamble Pharmaceuticals, Sanofi-Aventis and Servier, and he has conducted clinical trials for Procter \& Gamble Pharmaceuticals.

None delcared for George Ioannidis, Wilma Hopman, Noori AkhtarDanesh, Tassos Anastassiades, Laura Pickard, Courtney Kennedy, Jerilynn Prior, Kenneth Davison, Lehana Thabane or Amiran Gafni.

Contributors: Alexandra Papaioannou, Wilma Hopman, Tassos Anastassiades, Laura Pickard, Jerilynn Prior, Wojciech Olszynski, David Goltzman and Emmanuel Papadimitropoulos made substantial contributions to the conception of the study. George Ioannidis, Akhtar-Danesh, Jacques Brown, Robert Josse, David Hanley and Jonathan Adachi made substantial contributions to the conception and design of the study. All of the authors contributed to the interpretation of the data, critically revised the manuscript for important intellectual content and gave final approval for publication.
Funding: No external funding was received for this research. George Ioannidis was supported by the Strategic Training Program in Skeletal Health Research grant from the Canadian Institutes of Health Research.

\section{REFERENCES}

1. Goeree R, O'Brien B, Pettitt D, et al. An assessment of the burden of illness due to osteoporosis in Canada. J Soc Obstet Gynaecol Can 1996;(Suppl):15-24.

2. Adachi JD, Ioannidis G, Pickard L, et al. The association between osteoporotic fractures and health-related quality of life as measured by the Health Utilities Index in the Canadian Multicentre Osteoporosis Study (CaMos). Osteoporos Int 2003;14:895-904.

3. Center JR, Nguyen TV, Schneider D, et al. Mortality after all major types of osteoporotic fractures in men and women: an observational study. Lancet 1999;353:878-82.

4. Katelaris AG, Cumming RG. Health status before and mortality after hip fracture. Am J Public Health 1996:86:557-60.

5. Forsen L, Sogaard AJ, Meyer HE, et al. Survival after hip fracture: short- and longterm excess mortality according to age and gender. Osteoporos Int 1999;10:73-8.

6. Ismail AA, O'Neill TW, Copper C, et al. Mortality associated with vertebral deformity in men and women: results from the European Prospective Osteoporosis Study (EPOS). Osteoporos Int 1998;8:291-7.

7. Kanis JA, Oden A, Johnell O, et al. Excess mortality after hospitalization for vertebral fracture. Osteoporos Int 2004;15:108-12.

8. Kado DM, Browner WS, Palermo L, et al. Vertebral fractures and mortality in older women: a prospective study. Arch Intern Med 1999;159:1215-20.

9. Fransen M, Woodward M, Norton R, et al. Excess mortality or institutionalization after hip fracture: men are at greater risk than women. J Am Geriatr Soc 2002;50:685-90.

10. Alegre-Lopez J, Cordero-Guevara J, Alonso-Valdivielso J, et al. Factors associated with mortality and functional disability after hip fracture: an inception cohort study. Osteoporos Int 2005;16:729-36.

11. Cauley JA, Thompson DE, Ensrud KC, et al. Risk of mortality following clinical fractures. Osteoporos Int 2000;11:556-61.

12. Johnell O, Kanis JA, Oden A, et al. Mortality after osteoporotic fractures. Osteoporos Int 2004;15:38-42.

13. Kreiger N, Tenenhouse A, Joseph L, et al. The Canadian Multicentre Osteoporosis Study (CaMos): background, rationale, methods. Can J Aging 1999;18:376-87.

14. Brown JP. Josse RG.; the Scientific Advisory Council of the Osteoporosis Society of Canada. 2002 Clinical practice guidelines for the diagnosis and management of osteoporosis in Canada. CMAJ 2002;167:S1-34.

15. Ware JE. SF-36 health survey manual and interpretation guide. Boston (MA): The Health Institute, New England Medical Centre; 1993.

16. Ware JE Jr, Kosinski M, Keller SD. SF-36 physical and mental summary scales: A user's manual. Boston (MA): The Health Institute, New England Medical Center; 1994.

17. Jackson SA, Tenenhouse A, Robertson L, et al. Vertebral fractures definition from population-based data: preliminary results from the Canadian Multicentre Osteoporosis Study (CaMos). Osteoporos Int 2000;11:680-7.

18. Browner WS, Pressman A, Nevitt MC, et al.; Study of osteoporotic fractures research group. Mortality following fractures in older women: the study of osteoporotic fractures. Arch Intern Med 1996;156:1521-5.

19. Robbins JA, Biggs ML, Cauley J. Adjusted mortality after hip fracture: From the cardiovascular health study. J Am Geriatr Soc 2006;54:1885-91.

20. Magaziner J, Simonsick EM, Kashner TM, et al. Predictors of functional recovery one year following hospital discharge for hip fracture: a prospective study. J Gerontol 1990;45:M101-7.

21. Leidig G, Minne HW, Sauer P, et al. A study of complaints and their relationship to vertebral destruction in patients with osteoporosis. Bone Miner 1990;8:217-29.

22. Powell LM, Slater S, Chaloupka FJ, et al. Availability of physical activity related facilities and neighborhood demographic and socioeconomic characteristics: a national study. Am J Public Health 2006;96:1676-80.

23. Marcus EN. The silent epidemic-the health effects of illiteracy. N Engl J Med 2006;355:339-41.

24. Trone DW, Kritz-Silverstein D, von Mühlen DG, et al. Is radiographic vertebral fracture a risk factor for mortality? Am J Epidemiol 2007;166:1191-7.

Correspondence to: Dr. George Ioannidis, 501-25 Charlton Ave. E., Hamilton ON L8N 1Y2; fax 519 579-8341; g.ioannidis@sympatico.ca 